\title{
Conhecer para prevenir: complementação do conhecimento dos alunos do ensino fundamental sobre microbiologia e parasitologia em três escolas de Uberlândia-MG
}

\section{Know to prevent: complementation of the knowledge of the students of fundamental education on microbiology and parasitology in three schools of Uberlândia-MG}

\author{
Marco Miguel de Oliveira ${ }^{1}$, Kelem Cristina Pereira Mota ${ }^{2}$, Iasmin Aparecida \\ Cunha Araújo ${ }^{3}$, Karen Ferraz Faria ${ }^{4}$, Camila Oliveira Silva ${ }^{4}$, Douglas Alves \\ Pereira $^{5}$, Maria Júlia Rodrigues da Cunha ${ }^{4}$, Juliana Silva Miranda ${ }^{6}$
}

\section{Resumo}

\begin{abstract}
O conhecimento sobre microbiologia e parasitologia é considerado abstrato, pois muitos agentes causadores de doenças não são vistos a olho nu, o que distancia os alunos da realidade. Assim, nossos objetivos foram promover ações educativas por meio de ferramentas didáticas lúdicas que possibilitassem a complementação do aprendizado dos alunos frente aos diferentes grupos de microorganismos e parasitos e das ações de profilaxia relacionadas aos mesmos, e avaliar se ao final eles tinham condições de discriminar os grupos e relacionar com as doenças e as formas de profilaxia. Para tanto, foram feitas entrevistas junto aos professores para levantamento das possíveis atividades a serem desenvolvidas. A ação foi definida e então dividida em três momentos (aula expositiva, jogo didático e mostra científica) realizados entre agosto e novembro de 2018, atingindo aproximadamente 350 alunos, de oitavos e nonos anos, de três escolas públicas da zona urbana e rural da cidade de Uberlândia-MG. Para avaliar o impacto da ação foi feita uma análise comparativa de questionários aplicados antes (pré-intervenção) e após a ação (pós-intervenção). O percentual das respostas corretas nos questionários pós-intervenção aumentou em duas escolas ( $\mathrm{p}>0,005)$. Quanto à análise por questões, as menores porcentagens de acertos foram observadas em perguntas relacionadas à distinção entre doenças bacterianas e virais, o reconhecimento dos sintomas e a associação das formas de transmissão com a profilaxia. Assim, este estudo reforça a importância da educação em saúde para que os alunos se mobilizem frente ao combate das doenças.
\end{abstract}

Palavras-chave: Educação. Saúde. Prevenção.

${ }^{1}$ Doutorando em Imunologia e Parasitologia Aplicadas na Universidade Federal de Uberlândia (UFU), Uberlândia, Minas Gerais, Brasil. Docente na Universidade do Estado de Minas Gerais (UEMG), Ituiutaba, Minas Gerais, Brasil.

2 Doutoranda em Imunologia e Parasitologia Aplicadas na Universidade Federal de Uberlândia, Uberlândia, Minas Gerais, Brasil.

${ }^{3}$ Doutoranda em Imunologia e Parasitologia Aplicadas na Universidade Federal de Uberlândia, Uberlândia, Minas Gerais, Brasil. E-mail: iasminaraujo2006@hotmail.com

${ }^{4}$ Doutorado em Imunologia e Parasitologia Aplicadas pela Universidade Federal de Uberlândia, Uberlândia, Minas Gerais, Brasil.

${ }^{5}$ Mestrado em Imunologia e Parasitologia Aplicadas pela Universidade Federal de Uberlândia, Uberlândia, Minas Gerais, Brasil.

${ }^{6}$ Doutorado em Imunologia e Parasitologia Aplicadas pela Universidade Federal de Uberlândia, Uberlândia, Minas Gerais, Brasil. Técnica em Educação no Inst. de Ciências Biomédicas da Universidade Federal de Uberlândia, Uberlândia, Minas Gerais, Brasil. 


\begin{abstract}
The knowledge about microbiology and parasitology is considered abstract since causative agents of diseases cannot be seen with the naked eye, leading to students' detachment from reality. Therefore, this work aimed to promote educational actions through playful tools that could complement students' learning regarding the different groups of microorganisms and parasites and the prophylactic measures related to them. Furthermore, at the end of the actions it was evaluated if the students were able to discriminate the groups of microorganisms and relate them to the diseases they cause and the different forms of prophylaxis. To this end, interviews were conducted with teachers to survey the possible activities that could be used. The action was defined and then divided into three moments (expository class, didactic game and scientific show) held between August and November 2018, reaching approximately 350 students, from the eighth and ninth years, from three public schools in the urban and rural area of the city of Uberlândia-MG. To assess the impact of the action, a comparative analysis of questionnaires was applied before (pre-intervention) and after the action (post-intervention). The percentage of correct answers in the questionnaires post-intervention increased in two schools ( $>0,005)$. Regarding the analysis by questions, the lowest percentages of correct answers were observed in questions related to the distinction between bacterial and viral diseases, the recognition of the symptoms and the association of transmission ways with prophylaxis. Thus, this study reinforces the importance of health education for students to mobilize in the fight against diseases.
\end{abstract}

Keywords: Education. Health. Prevention.

\section{Introdução}

As doenças infectocontagiosas e parasitárias apresentam relevante importância médico-social em países com baixa renda per capita, uma vez que podem produzir déficit orgânico que afeta o desenvolvimento normal de crianças, gerarem quadros debilitantes que se manifestam de formas variadas, promoverem comorbidades que limitam a vida da população e causar o óbito de indivíduos, principalmente os imunocomprometidos..$^{(1-2)}$ Essas enfermidades acometem uma porcentagem significativa da populaçãobrasileira, principalmente em comunidades de baixa renda, as quais vivem em regiões desfavorecidas geopoliticamente e que apresentam condições climáticas e ambientais favoráveis para a propagação das mesmas. ${ }^{(3-4)}$

Sabe-se que crianças e adolescentes são mais susceptíveis a infecções devido a hábitos precários de higiene, desconhecimento de determinadas medidas profiláticas, ausência de imunidade efetiva contra alguns agentes infecciosos e, principalmente, maior exposição ocasionada por comportamentos de risco. ${ }^{(5-8)}$ Assim, considerando que o indivíduo em idade escolar é um potencial disseminador e multiplicador de informações para a família, grupos de amigos e outros membros da comunidade, preconiza-se o ensino de tópicos referentes à microbiologia e parasitologia com o intuito de estimular a autonomia do educando no cuidado da própria saúde. ${ }^{(9-10)}$ Nas escolas, entretanto, a temática Saúde ganhou maior destaque somente após ser introduzida nos temas transversais dos Parâmetros Curriculares Nacionais (PCNs), mais especificamente no eixo temático Ser Humano e Saúde. ${ }^{(9,11-12)}$ Desde então, trabalhar a prevenção de determinadas moléstias e sua relação com o homem tornou-se uma das funções da escola.

No contexto social, a disseminação de informações sobre a transmissão e profilaxia de doenças possibilita que o cidadão conheça e se previna de uma possível infecção. ${ }^{(13)}$ Contudo, o mundo dos micro-organismos ainda é considerado abstrato no imaginário popular, pois esses agentes não podem ser vistos a olho nu ou sequer percebidos por outros sentidos, o que torna difícil a compreensão de que seres tão pequenos apresentem tamanha relevância. ${ }^{(14)}$ E diante disso, muitas vezes, não é dada a devida importância para a apresentação de alguns sinais característicos da infecção e/ou parasitismo, bem como para a realização de exames específicos e as formas de prevenção da doença. 
Tais fatores fazem com que esses organismos sejam esquecidos no nosso dia a dia, inclusive na rotina escolar. Aliado a esse distanciamento, ao encontrar uma realidade em que a escola não possui infraestrutura para a execução de aulas práticas, por mais simples que sejam, e equipamentos laboratoriais (microscópios, lupas e lâminas), alguns professores negligenciam os conteúdos de microbiologia e parasitologia ou ministram aulas que são meras representações do livro didático. ${ }^{(15-16)}$

Uma vez que a disciplina de Ciências apresenta alguns temas que exigem maior abstração do aluno, a utilização de alternativas que auxiliem no entendimento de determinados conceitos é de extrema importância. ${ }^{(17)}$ Nesta perspectiva, as atividades lúdicas (jogos, dinâmicas e modelos didáticos) possibilitam uma melhor compreensão e apropriação dos saberes, bem como promovem um ambiente motivador, de estímulo à criatividade, da cooperação e participação ativa na construção do conhecimento. ${ }^{(12,18)}$ No entanto, esses recursos ainda são pouco empregados na realidade escolar, se comparados ao uso da aula expositiva. Isso se dá pelo fato do ensino de Ciências ainda estar pautado em um modelo de educação tradicional e tecnicista, ou seja, apresentar um grande enfoque na transmissão do conhecimento sem sua devida problematização, interpretação e aplicação na vida do aluno. ${ }^{(19)}$ Vale ressaltar alguns pontos importantes para a efetivação da emancipação do educando; são eles: construção de uma visão política que garanta ampla interpretação do mundo contemporâneo, formação pautada na responsabilidade ética, participação da comunidade na escola, o envolvimento dos professores e coordenadores pedagógicos na construção de um projeto político pedagógico que vise uma educação progressista e libertária, bem como investimentos na formação continuada e capacitação dos docentes. ${ }^{(14,20-22)}$

Diante do que foi exposto e da importância de promover ações educativas com foco em saúde, este trabalho teve como objetivo desenvolver ferramentas didáticas a fim de complementar o aprendizado de microbiologia e parasitologia e avaliar se os alunos foram capazes, ao fim das atividades, de reconhecer os diferentes grupos de agentes causadores de doenças, associando-os às enfermidades e suas formas de prevenção.

\section{Metodologia}

Este estudolongitudinal descritivo quantitativo foi realizado em três escolas públicas de ensino fundamental da cidade de Uberlândia (MG), sendo elas duas escolas municipais, uma na área urbana (A) e outra na zona rural (B) e a terceira estadual na área urbana (C). As escolas foram definidas por meio da manifestação de interesse no primeiro contato via telefone. Frente a isso, foi solicitada a autorização junto a Secretária de Educação do Município de Uberlândia para a realização desse trabalho, sendo ele também cadastrado no Sistema de Informação de Extensão da Universidade Federal de Uberlândia (número de registro 17542).

As atividades teórico-práticas ocorreram entre agosto e novembro de 2018, sendo realizadas com cinco turmas de oitavo ano e cinco turmas de nono ano do ensino fundamental de todas as três escolas. A escolha destas séries se deu pelo fato de que os conteúdos de microbiologia e parasitologia são abordados no sétimo ano do ensino fundamental, assim os alunos já haviam tido contato com os mesmos. Na primeira visita in loco, os objetivos do projeto foram apresentados aos coordenadores pedagógicos (diretores e vice-diretores); também foram entregues questionários para as duas professoras responsáveis pelo conteúdo de Ciências (uma da Escola A e C, e outra da Escola B). Esses questionários se referiam às demandas das escolas em relação aos problemas que as docentes encontravam ao trabalharem microbiologia e parasitologia, quais as dificuldades de aprendizagem dos alunos, quais metodologias são mais utilizadas nas aulas e quais estratégias alternativas deveriam ser utilizadas na realização das atividades.

A ação foi planejada com base na análise dos relatos das professoras. A partir das necessidades apontadas, as atividades com os alunos foram elaboradas para contemplar três diferentes momentos, conforme mostrado na Figura 1. 
Figura 1 - Diagrama resumindo as atividades realizadas nos diferentes momentos nas três escolas.

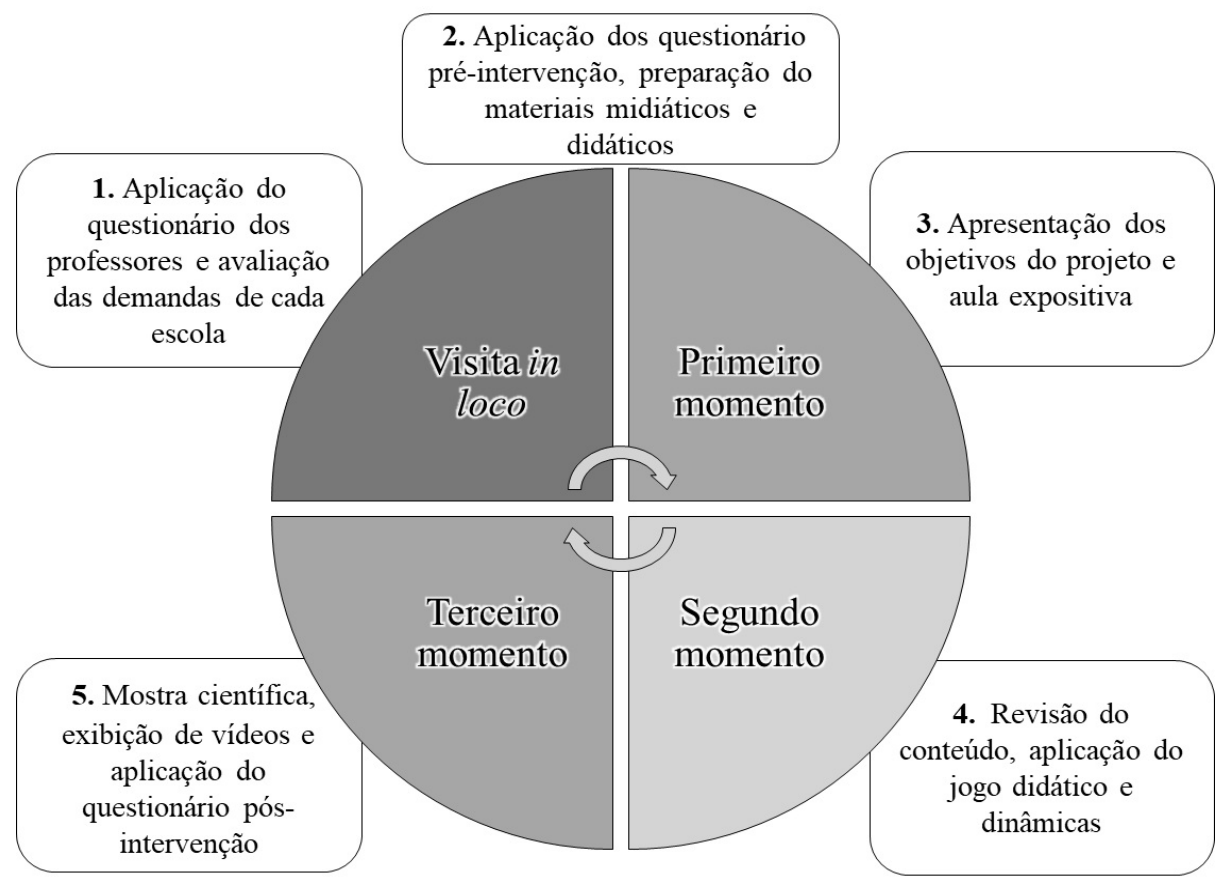

Fonte: Autores

\section{Primeiro momento}

O primeiro momento consistiu da apresentação da equipe e da finalidade do projeto aos alunos, seguido de uma aula expositiva que contou com auxílio de material didático (banners sobre parasitos, vírus e bactérias), bem como modelos desmontáveis de vírus e bactéria confeccionados em material emborrachado; e slides abordando a biologia (morfologia básica, formas de transmissão e prevenção) dos diferentes organismos pertencentes aos grupos de agentes prejudiciais à saúde humana e animal.

\section{Segundo momento}

No segundo momento, os alunos participaram de oficinas relacionadas aos temas trabalhados no encontro anterior. Tais oficinas envolveram a realização da dinâmica "Dança das cadeiras: micro-organismos a solta", do jogo de tabuleiro "Mundo da Parasitologia" e de um quiz.

Para a dinâmica "Dança das cadeiras: microorganismos a solta", as cadeiras foram organizadas no centro da sala de aula em forma de círculo, com uma cadeira a menos do que o número total de alunos. Os participantes deveriam se locomover ao redor das cadeiras durante a execução de uma música e, quando esta fosse pausada, eles deveriam se sentar. Aquele aluno que ficasse sem cadeira deveria retirar uma pergunta. Após respondida, os demais estudantes que participavam da prática deveriam avaliar se a resposta estava correta ou não. Caso a resposta estivesse certa, o aluno poderia eliminar uma das pessoas sentadas, se estivesse errada ele seria eliminado. Em seguida, a pergunta era explicada pelos mediadores. Passadas algumas rodadas, os eliminados poderiam responder perguntas selecionadas e, caso a resposta estivesse correta, eliminar um dos competidores restantes e retornar para a dinâmica.

Para o jogo "Mundo da Parasitologia" foram desenvolvidas cartas e um tabuleiro (material suplementar - https://drive.google.com/open?id= 1f2PKgairK1OXPPF1ToRTOKchxfD83Fja), no qual os grupos formados pelos alunos deveriam avançar com suas respectivas peças pelas casas até a chegada. Para isso, eles deveriam lançar um 
dado e retirar uma "carta pergunta". As perguntas deveriam ser respondidas com "sim" ou "não" e justificadas, os demais alunos julgavam a resposta e caso confirmassem que estava correta, o grupo poderia avançar a quantidade de casas indicadas pelo dado. O tabuleiro também contava com "casas surpresa", onde os alunos deveriam retirar cartas relacionadas a "decisões saudáveis", que continham bonificações ("avance duas casas"), ou "decisões não saudáveis" que correspondiam a uma penalidade ("retorne duas casas") ilustradas na Figura 2A, "casas com penalidades" (ficar sem jogar uma rodada) ou "casas apresentação" (Figura 2B), na qual eles deveriam retirar cartas que apresentavam um parasito não trabalhado no primeiro momento. Tais cartas deveriam ser lidas em voz alta e, em seguida, era realizada a explicação pelos mediadores.

Figura 2 - Jogo "Mundo da Parasitologia" utilizado no segundo momento. Exemplos de carta surpresa de decisão saudável e não saudável (A) e carta apresentação (B).
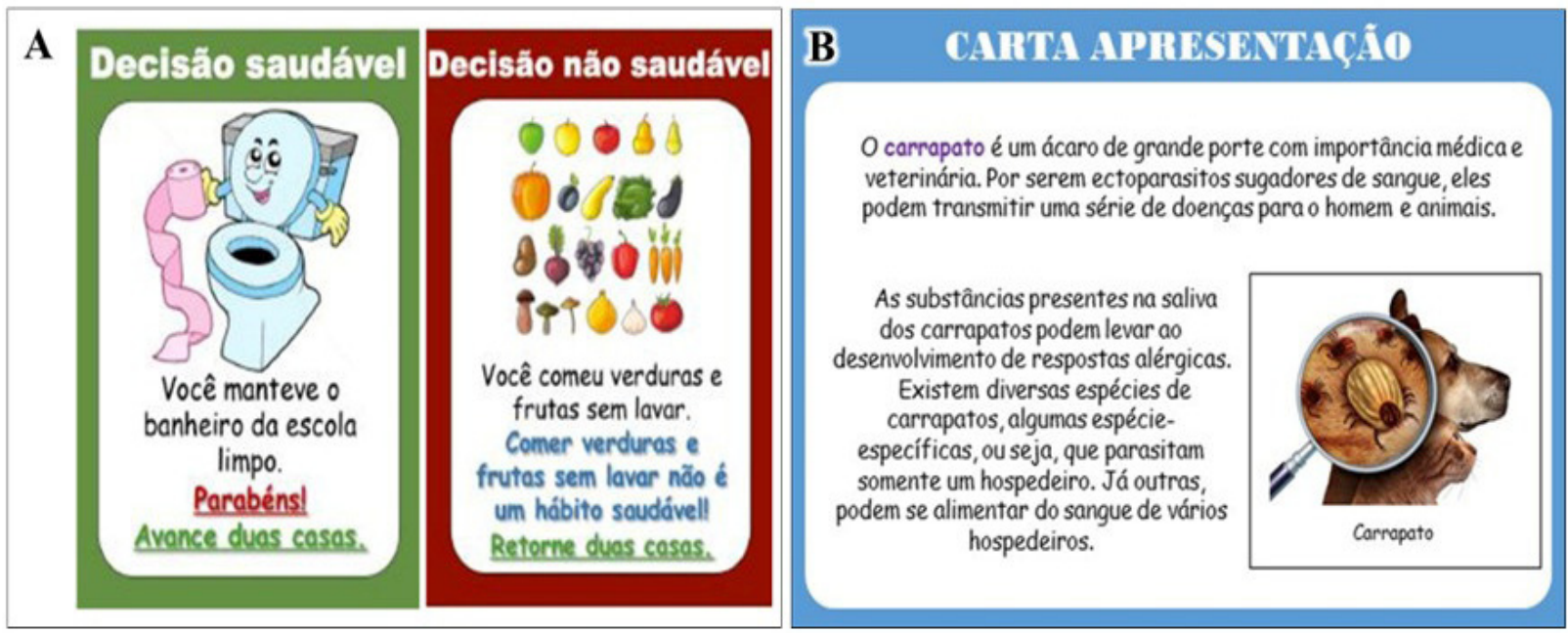

Fonte: Autores

O quiz consistia em perguntas que foram exibidas no projetor e placas de verdadeiro ou falso confeccionadas em material emborrachado. Ao início da atividade, os alunos foram separados em grupos de cinco a dez integrantes. Após a exibição e leitura das perguntas, os estudantes tinham cinco minutos para discutir a resposta entre si. Após esse tempo, cada grupo deveria levantar a placa com sua resposta, sendo esta discutida pelos mediadores com o auxílio da turma.

\section{Terceiro momento}

No terceiro e último momento foi realizada uma mostra científica, no qual foram expostas placas de cultura bacteriana e lise celular causada por vírus, cedidas pelos Laboratórios de
Microbiologia Molecular e Virologia do Instituto de Ciências Biomédicas da Universidade Federal de Uberlândia (ICBIM/UFU), além de exemplares de parasitos intestinais - formas adultas e larvais e lâminas com ovos, emprestados do acervo do Laboratório de Ensino de Parasitologia do Departamento de Parasitologia da universidade (ICBIM/UFU), assim como os microscópios e estereomicroscópios utilizados para a visualização dos organismos.

Este evento ainda contou com a exposição de todo o material didático produzido durante o projeto, a exibição de vídeos sobre a prevenção de algumas doenças e a entrega de folders informativos, tanto confeccionados pelos autores desse trabalho, quanto cedidos pela Prefeitura Municipal de Uberlândia. 


\section{Avaliação}

Para averiguar os conhecimentos prévios dos alunos, os quais não foram identificados em nenhum momento do trabalho, foi desenvolvido um questionário pré-intervenção (contendo quatorze perguntas sobre biologia geral, formas de transmissão e prevenção de algumas doenças infectocontagiosas e parasitárias) que foi aplicado como atividade curricular pelas professoras responsáveis pelo conteúdo de Ciências.

Com o intuito de verificar a assimilação das informações e apropriação do conhecimento após os três momentos do presente trabalho, o mesmo questionário foi aplicado novamente aos estudantes pelas professoras, sendo que o critério para o preenchimento foi de ter participado de, no mínimo, um momento da ação. As porcentagens de acertos foram analisadas usando o programa GraphPad Prism 7.0 (GraphPad Software Inc., San Diego, CA, EUA), sendo submetidas à análise estatística pelo teste de Friedman, considerando valores com $\mathrm{p}<0,05$ estatisticamente significantes.

\section{Resultados}

Por meio do questionário respondido pelas professoras foi constatada a importância de ações que abordassem conteúdos relativos à saúde individual e coletiva, principalmente tópicos que envolviam as infecções sexualmente transmissíveis (ISTs) e doenças parasitárias. Neste quesito, uma das professoras (Escola B) respondeu que seria importante abordar nas atividades as doenças que fazem parte da realidade dos alunos que vivem na zona rural; por exemplo: a raiva transmitida por animais silvestres, infecções relacionadas com a má qualidade da água e a infestação por carrapatos. Dessa forma, foram elaborados materiais midiáticos e didáticos que contemplassem aspectos relacionados à prevenção de doenças como: gripe, dengue, raiva, hepatites virais (A, B, C e D), herpes, papiloma, infecção pelo vírus da imunodeficiência humana (HIV), imunodeficiência humana adquirida (AIDS), tuberculose, disenteria bacteriana, cólera, cárie, gonorreia, sífilis, giardíase, criptosporidíase, ascaridíase, ancilostomíase, teníase, cisticercose, tungíase e pediculose. Além disso, no jogo "Mundo da Parasitologia" também foram explorados a infestação por carrapatos, esquistossomose, oxiurose, amebíase, malária, leishmaniose e tripanossomíase.

Sobre as principais dificuldades no ensinoaprendizagem dos conteúdos de microbiologia e parasitologia, foram apontados problemas na abordagem da morfologia dos vírus, bactérias e parasitos, uma vez que os alunos não compreendem os aspectos estruturais desses diferentes organismos somente com aulas expositivas. Dessa forma, modelos didáticos de vírus e bactérias foram confeccionados para relembrar a estrutura básica desses micro-organismos, bem como para contextualizar tópicos importantes de sua biologia, por exemplo: a importância do envelope viral para reconhecimento e entrada do vírus na célula e a existência do flagelo para locomoção de algumas bactérias. Nos questionários também foi apontada a dificuldade em mostrar os agentes etiológicos de determinadas doenças, quer seja no microscópio ou a exibição de exemplares de macroparasitos conservados, evidenciando a escassez de materiais laboratoriais nas escolas (coleção de lâminas e material biológico fixado). Das metodologias mais utilizadas pelas docentes, a aula expositiva e o uso pontual de imagens foram citadas como as mais empregadas. Assim, foi destacada, como sugestão para os três momentos, a importância de atividades práticas e oficinas que priorizassem a participação ativa e a interação dos alunos.

De forma geral, a atividade de extensão alcançou aproximadamente 350 alunos, sendo preenchidos 251 questionários pré-intervenção e 227 pós-intervenção em todas as três escolas. Na Tabela 1 é possível observar as características da população de alunos que responderam os questionários. 
Tabela 1 - Características da população que compôs o estudo, quantidade de acertos e erros nos questionários pré-intervenção e pós-intervenção.

\begin{tabular}{|c|c|c|c|}
\hline Características & Escola A & Escola B & Escola C \\
\hline \multicolumn{4}{|c|}{$N$} \\
\hline Pré-intervenção & 77 & 43 & 131 \\
\hline Pós-intervenção & 76 & 30 & 121 \\
\hline \multicolumn{4}{|l|}{ Sexo: n (\%) } \\
\hline \multicolumn{4}{|l|}{ Masculino } \\
\hline Pré-intervenção & $40(52 \%)$ & $21(49 \%)$ & $63(48 \%)$ \\
\hline Pós-intervenção & $35(46 \%)$ & $11(37 \%)$ & $53(44 \%)$ \\
\hline \multicolumn{4}{|l|}{ Feminino } \\
\hline Pré-intervenção & $37(48 \%)$ & $22(51 \%)$ & $68(52 \%)$ \\
\hline Pós-intervenção & $41(54 \%)$ & $19(63 \%)$ & $68(56 \%)$ \\
\hline Média de idade & $15 \pm 2$ & $13 \pm 1$ & $14 \pm 1$ \\
\hline \multicolumn{4}{|c|}{ Frequência de acertos: $n(\%)$} \\
\hline Pré-intervenção & $51(67 \%)$ & $24(55 \%)$ & $78(59 \%)$ \\
\hline Pós-intervenção & $50(66 \%)$ & $20(65 \%)$ & $81(67 \%)$ \\
\hline \multicolumn{4}{|c|}{ Frequência de erros: $n(\%)$} \\
\hline Pré-intervenção & $26(33 \%)$ & $19(45 \%)$ & $53(41 \%)$ \\
\hline Pós-intervenção & $26(34 \%)$ & $10(35 \%)$ & $41(33 \%)$ \\
\hline
\end{tabular}

Fonte: Autores

Quanto ao percentual de acertos, foi possível perceber uma variação de $1 \%$ entre os questionários da Escola A (67\% no pré-intervenção / 66\% no pós-intervenção), 10\% da Escola B (55\% no préintervenção / $65 \%$ no pós-intervenção) e $8 \%$ da Escola C (59\% pré-intervenção / 67\% no pósintervenção), conforme a Tabela 1. Não foram observadas diferenças estatisticamente significativas em relação ao número de acertos entre as três escolas e entre os momentos avaliados ( $>>0,05)$.

No que se refere à apropriação de conhecimento após os três momentos, a Figura 3 apresenta as porcentagens de respostas corretas referentes a todas as escolas, tanto em relação aos questionários pré-intervenção quanto aos pós- intervenção, é possível verificar um aumento de acertos nas perguntas um $(7,8 \%)$, dois $(16,1 \%)$, três $(13,2 \%)$, cinco $(9,4 \%)$, seis $(3,1 \%)$, nove $(16,5 \%)$, dez $(9,9 \%)$, onze $(6,4 \%)$, doze $(5,1 \%)$ e quatorze (1\%), mesmo não sendo observada diferença estatisticamente significativa $(\mathrm{p}>0,05)$.

As questões dois, três, cinco, seis, nove, onze e doze apresentaram as menores frequências percentuais de respostas corretas nos questionários pré-intervenção e pós-intervenção em comparação às demais perguntas, revelando certa dificuldade dos alunos em distinguir doenças bacterianas de virais, reconhecer os sintomas de algumas enfermidades (tuberculose, gonorreia, sífilis, hepatite $\mathrm{C}$, giardíase e ascaridíase) e associar suas 
formas de transmissão com a profilaxia, em ambos verificar que as questões com maiores frequências os momentos avaliados. A Tabela 2 apresenta percentuais de acertos foram: um, quatro, sete, esses dados separados por escola, onde é possível oito, dez, treze e quatorze.

Figura 3 - Porcentagens de acertos por questão referentes aos questionários pré-intervenção e pós-intervenção considerando todos os alunos.

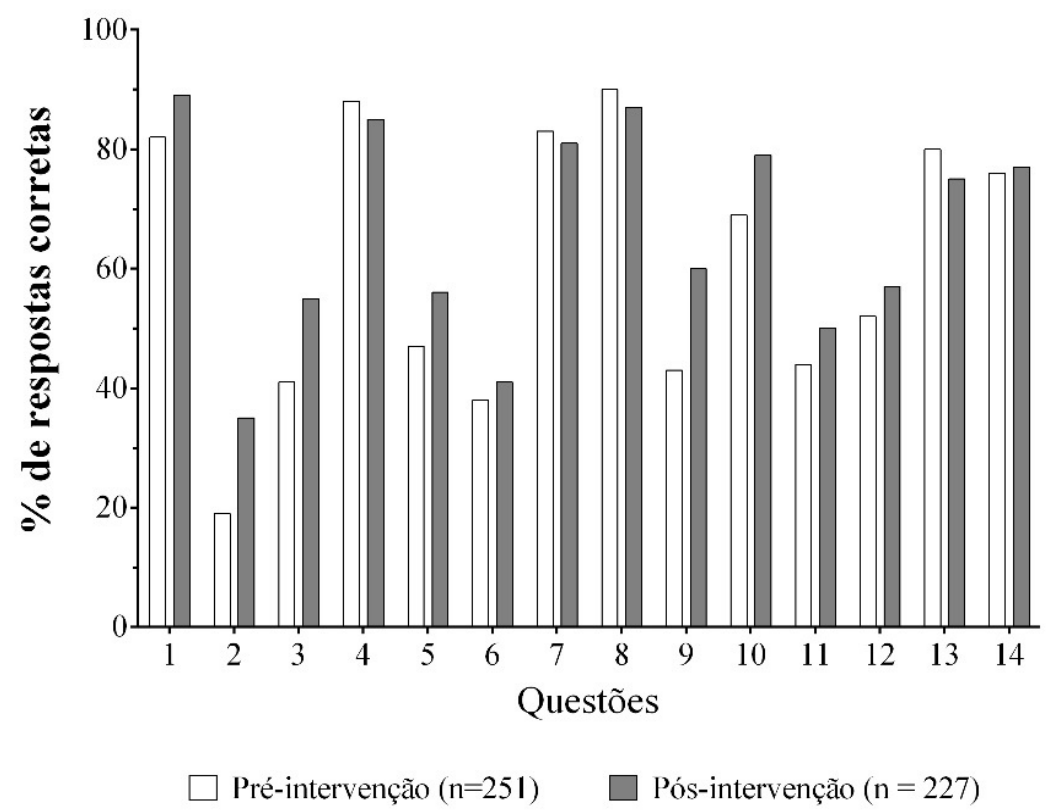

Fonte: Autores

Tabela 2 - Capacidades esperadas nas quatorze questões e suas respectivas porcentagens de acertos nos questionários pré-intervenção e pós-intervenção das três escolas analisadas.

\begin{tabular}{lccc}
\hline \multicolumn{1}{c}{ Questões } & Escola A & Escola B & Escola C \\
\hline $\begin{array}{l}\text { (1) Reconhecer o conjunto de micro-organismos causadores } \\
\text { de doenças em humanos }\end{array}$ & & & \\
$\quad$ Pré-intervenção & 80,5 & 79,1 & 83,2 \\
$\quad$ Pós-intervenção & 90,8 & 83,3 & 90,1 \\
(2) Reconhecer a gonorreia como doença bacteriana & & & \\
$\quad$ Pré-intervenção & 18,2 & 14,0 & 21,4 \\
$\quad$ Pós-intervenção & 30,3 & 43,3 & 36,4 \\
(3) Reconhecer como ocorre a transmissão da tuberculose & & & \\
$\quad$ Pré-intervenção & 50,6 & 41,9 & 35,9 \\
$\quad$ Pós-intervenção & 60,5 & 36,7 & 55,4 \\
(4) Reconhecer como ocorre a transmissão da disenteria bacteriana & & & \\
$\quad$ Pré-intervenção & 90,9 & 79,1 & 88,5 \\
$\quad$ Pós-intervenção & 86,8 & 80,0 & 84,3 \\
(5) Reconhecer como ocorre a transmissão da gonorreia e sífilis & & & \\
$\quad$ Pré-intervenção & 71,4 & 60,5 & 28,2 \\
$\quad$ Pós-intervenção & 69,7 & 56,7 & 47,9
\end{tabular}


Continuação

(6) Reconhecer quais doenças não são causadas por vírus

$$
\begin{aligned}
& \text { Pré-intervenção } \\
& \text { Pós-intervenção }
\end{aligned}
$$$$
41,6 \quad 32,6 \quad 37,4
$$

30,0

(7) Reconhecer como ocorre a transmissão do HIV e como se prevenir

$$
\begin{aligned}
& \text { Pré-intervenção } \\
& \text { Pós-intervenção }
\end{aligned}
$$$$
87,0
$$$$
69,8
$$$$
82,9
$$$$
76,7
$$

82,9

(8) Reconhecer como ocorre a transmissão da dengue e como se prevenir

$$
\begin{aligned}
& \text { Pré-intervenção } \\
& \text { Pós-intervenção }
\end{aligned}
$$$$
94,8 \quad 88,4 \quad 87,0
$$

(9) Reconhecer os sintomas e forma de transmissão da hepatite C

Pré-intervenção

Pós-intervenção

(10) Reconhecer como ocorre a transmissão da teníase

Pré-intervenção

Pós-intervenção

(11) Reconhecer como ocorre a transmissão da giardíase e como se prevenir

$$
\begin{aligned}
& \text { Pré-intervenção } \\
& \text { Pós-intervenção }
\end{aligned}
$$

60,5

32,6

41,2

56,7

60,3

67,5

73,7

46,5

77,1

83,3

81,0

49,4

53,5

37,4

50,0

53,3

49,6

(12) Reconhecer como ocorre a transmissão da ascaridíase e quais os principais sintomas
Pré-intervenção
Pós-intervenção
(13) Reconhecer como as vacinas funcionam e sua importância
Pré-intervenção
Pós-intervenção

61,0

30,2

54,2

53,9

56,7

59,5

$\begin{array}{lll}85,7 & 65,1 & 80,9 \\ 72,4 & 90,0 & 72,7\end{array}$

(14) Reconhecer quais hábitos comportamentais podem evitar infecções por micro-organismos
Pré-intervenção
83,1
74,4
72,5
Pós-intervenção
75,0
73,3

Fonte: Autores

\section{Discussão}

Doenças causadas por vírus, bactérias e parasitos acometem pessoas em todo o mundo, entretanto, nos países subdesenvolvidos observa-se maior prevalência de determinadas enfermidades, bem como maior número de casos debilitantes e de óbitos. ${ }^{(8)}$ Em regiões como o Brasil, por exemplo, infecções virais, bacterianas e parasitárias apresentam profundo impacto na saúde pública e qualidade de vida da população, o que muitas vezes ocasiona perdas econômicas e problemas sociais. ${ }^{(11)}$ Entre os indivíduos mais acometidos, crianças e jovens em idade escolar são apontados como o grupo de risco por serem mais susceptíveis ou apresentarem comportamentos que viabilizam a disseminação de determinadas infecções. ${ }^{(23)}$ Nesse sentido, a educação em saúde 
é de extrema relevância, uma vez que pode resultar na modificação de práticas consideradas não saudáveis e, consequentemente, na prevenção de determinadas doenças. ${ }^{(24)}$

Neste estudo foi realizado o levantamento, com duas professoras de Ciências que aceitaram participar e colaborar com a realização do trabalho, sobre quais eram as principais dificuldades ao abordarem assuntos referentes à microbiologia $\mathrm{e}$ parasitologia no ensino básico. Conforme apontado por Vasconcellos et al. ${ }^{(15)}$ e Silva et al. ${ }^{(25)}$ a relação entre educação e saúde está condicionada a muitos fatores que comprometem o aprendizado, destes destacam-se a falta de equipamentos e materiais necessários para a realização de aulas práticas e a dificuldade de organização do conteúdo por parte dos educadores. Nota-se, portanto, a escassez de artifícios pedagógicos que promovam a construção do conhecimento de forma satisfatória, o que vai ao encontro do que foi constatado nos questionários respondidos pelas professoras.

Frente ao exposto, Oda e Delizoicov(26) ressaltam que os conhecimentos no que se refere à educação em saúde têm sido apresentados sob uma abordagem fortemente conceitual, com ausência de contextualização e problematização sobre o perfil epidemiológico atual das doenças. Além disso, considerando que o processo de ensinoaprendizagem vem sendo tratado nas escolas brasileiras com uma pretensa neutralidade social e política, ${ }^{(27)}$ convém destacar também a importância de que o conteúdo ensinado estabeleça conexão com a realidade dos estudantes, como preconizado nos PCNs. ${ }^{(9)}$ Nesta perspectiva, Oliveira e Gonçalves ${ }^{(28)}$ também apontam a necessidade de que as ações educativas de promoção à saúde sejam planejadas de forma a provocar conflito nos indivíduos, pois somente assim cria-se a oportunidade para que o mesmo repense seus hábitos e possa transformar sua realidade. Evidenciado os problemas do ensino tradicional, o lúdico tem despontado como alternativa viável para complementação dos saberes e a garantia de uma aprendizagem significativa.

Considerando a educação como um importante fator para a prevenção de doenças infectocontagiosas e parasitárias, foram pensadas ações que priorizassem a complementação dos saberes dos alunos sobre essas enfermidades. Para tal, foram desenvolvidas atividades lúdicas e modelos didáticos que, conforme Viveiro e Diniz, ${ }^{(29)}$ Candeias et al. ${ }^{(30)}$ e Braga et al. ${ }^{(31)}$ fogem do esquema tradicional de aulas teóricas por tornar o momento mais dinâmico, interativo, prazeroso e propício a uma melhor visualização e mentalização dos conceitos apresentados. Durante os momentos junto aos alunos foi observada uma atmosfera de entusiasmo e empolgação, reforçando o papel da ludicidade como forma de estimular a aprendizagem, cooperação e o senso de coletividade. No contexto das atividades relatadas, vale ressaltar que os dois últimos pontos citados são essenciais para a efetivação das medidas de prevenção. ${ }^{(32)}$ Contudo, além dessa percepção, analisamos a apropriação dos conhecimentos passada nos três momentos, por meio da análise dos questionários pré-intervenção e pósintervenção. Essa metodologia foi escolhida pois, segundo Ribeiro, ${ }^{(33)}$ a utilização de questionários garante o anonimato dos indivíduos amostrados e os resultados podem ser facilmente organizados e convertidos em valores numéricos.

Ao analisar a porcentagem geral de acertos nos questionários pré-intervenção identificamos maior tendência aos acertos, o que pode indicar que em alguns temas o conhecimento prévio dos alunos era relevante, fato esse importante, pois é a partir desse conhecimento prévio que há a possibilidade de uma ancoragem dos novos conceitos, permitindo assim que o aluno possa organizar, compreender e fixar as novas informações. ${ }^{(34)} \mathrm{Na}$ comparação dos questionários pré-intervenção com o pósintervenção foi constatada sutil diferença das porcentagens nas três escolas; em algumas questões verificou-se aumento de respostas corretas, o que, conforme Ausubel, ${ }^{(35)}$ corresponde ao fato de que alunos, mesmo em posse de conhecimentos prévios, ainda podem incorporar novos conceitos aos existentes e reforçar seus saberes. Isso se dá, pois há conhecimentos prévios relevantes que servem com subsunçores, e assim nessa interação 
com novas informações há um somatório, permitindo a modificação do conhecimento, o que é particular de cada aluno. ${ }^{(34)}$

Quanto às questões com menores porcentagens gerais de acertos, as respostas podem refletir o desconhecimento de aspectos importantes sobre determinadas doenças por parte dos alunos. Aliado a isso, alguns alunos não mostram a aplicabilidade do que foi aprendido em suas atitudes cotidianas, fato percebido nos primeiros momentos, quando no intervalo ou na ida ao banheiro alguns indivíduos negligenciavam cuidados básicos como lavar as mãos e os alimentos. ${ }^{(36)}$ Ambos os apontamentos evidenciam a existência de lacunas entre o nível de conhecimento e a adoção efetiva de práticas saudáveis. Ainda nessa perspectiva, convém destacar a importância de ações continuadas que integrem toda a escola e comunidade onde ela está inserida. Gomes, ${ }^{(32)}$ ao discutir o papel da Educação em Saúde na formação de jovens, propõe que as escolas devem promover o debate e implementação de um estilo de vida compatível com o desenvolvimento da saúde em toda a sociedade.

Com isto, apesar de não verificarmos diferença estatisticamente significante na apropriação do conhecimento foi percebido muito engajamento proporcionado pelas atividades lúdicas e práticas que abordavam conteúdo sobre hábitos comportamentais saudáveis e a sua prática na rotina, além das formas de prevenção, o que permitiu que os alunos fossem sensibilizados para colaborar com o ambiente que vivem e transmitir seus conhecimentos para outras pessoas. ${ }^{(7)}$

\section{Conclusão}

Aspectos importantes dentro dos conteúdos de microbiologia e parasitologia são muitas vezes negligenciados, seja por falta de uma estrutura que dê suporte para garantia da aprendizagem efetiva ou devido à falta de recursos pedagógicos. Assim, a promoção da educação em saúde em escolas públicas, que ainda possuem uma realidade distante das necessidades práticas dos alunos, faz-se necessária. Projetos de extensão com este cunho contribuem para a sensibilização de todo o corpo escolar e causa maior mobilização de todos, não só nas escolas, mas também na sociedade.

\section{Agradecimentos}

Agradecemos às representantes das escolas envolvidas nesse trabalho, às professoras, supervisoras e diretoras que contribuíram para a implantação e execução do projeto, à Prefeitura Municipal de Uberlândia que por meio da Secretaria de Saúde nos doou panfletos e folders, bem como à Universidade Federal de Uberlândia que por meio da Pró-reitoria de Extensão e Cultura (PROEXC) e seus editais de fomento de atividades extensão, nos permitiu a realização do presente trabalho.

\section{Referências}

1 Boeira VL, Gonçalves PARR, Morais FG, Schaedler VM. Educação em saúde como instrumento de controle de parasitoses intestinais em crianças. Varia Sci. 2010;62(15): 35-43.

2 Murray CJL, Vos T, Lozano R, Naghavi M, Flaxman AD, Michaud C, et al. Disabilityadjusted life years (DALYs) for 291 diseases and injuries in 21 regions, 1990-2010: a systematic analysis for the Global Burden of Disease Study 2010. Lancet. 2012;380(9859):2197-223. doi: 10.1016/S0140-6736(12)61689-4.

3 Carvalheiro JR. Epidemias em escala mundial e no Brasil. Estud Av. 2008;22(64):7-17. doi: 10.1590/S0103-40142008000300002.

4 Sousa, TCM, Amancio F, Hacon SS, Barcellos C. Doenças sensíveis ao clima no Brasil e no mundo: revisão sistemática. Rev Panam Salud Publica. 2018;42(23). doi: 10.26633/ RPSP.2018.85.

5 Montresor A, Crompton DW, Gyorkos TW, Savioli L. Helminth control in schoolage children: a guide for managers of control programmes. Geneva: World Health Organization; 2002. 
6 Galvani AP. Age-dependent epidemiological patterns and strain diversity in helminth parasites. J Parasitol. 2005;91(1):24-30. doi: 10.1645/GE-191R1.

7 Toscani NV, Santos AJDS, Silva LLM, Tonial CT, Chazan M, Wiebbelling AMP, et al. Development and analysis of an educational game for children aiming prevention of parasitological diseases. Interface 2007;11(22):281-94. doi: 10.1590/S141432832007000200008 .

8 Ministério da Saúde. Plano Nacional de Vigilância e Controle das Enteroparasitoses. Brasília: Ministério da Saúde; 2005.

9 Ministério da Educação. Parâmetros curriculares nacionais: Temas Transversais Saúde. Brasília: MEC; 1998.

10 Frezza TF, Correa SAP, Santos-Rondon M V S, Prado CCR, Bastos LAD, Allegretti SM. Alunos do ensino médio de escolas da rede pública de Campinas-SP atuando como produtores de conhecimento sobre parasitoses: Uma experiência do laboratório de helmintologia (UNICAMP) no programa "Ciência e arte nas férias". Rev Conexão UEPG. 2015;11(2):128-39.

11 Grimes C, Ronchi DL, Hirano ZMB. Prática pedagógica diferenciada nos processos de ensinar e de aprender em Parasitologia. Ensino Saúde Ambient. 2013;6(1):89-100. doi: 10.22409/resa2013.v6i1.a21007.

12 Nascimento AMD, Luca Junior W, Santos, RLC, Dolabella SS. Parasitologia Lúdica: O jogo como agente facilitador na aprendizagem das parasitoses. Scientia Plena. 2013;9(7).

13 Rosadas, C. "Quem sou eu? Jogo dos vírus": Uma Nova Ferramenta no Ensino da Virologia. Rev.Bra.Educ. Méd.2012;36(2):264-68, 2012. doi: 10.1590/S0100-55022012000400016.

14 Siqueira MP, Azevedo EP, Almeida EM, Matos JS, Rodrigues AR, Scarabelli $\mathrm{SC}$, et al. Conhecimentos de escolares e funcionários da Rede Pública de Ensino sobre as parasitoses intestinais. Rev. Inst. Adolfo Lutz. 2016;75:1-12.
15 Cassanti, A.C.; Cassanti, A.C.; Araújo, E.E. Microbiologia democrática: estratégias de ensino-aprendizagem e formação de professores. Rev. Conhecer. 2008;9(1):84-93.

16 Vasconcellos MMM, Oliveira CC, Berbel NAN. O professor e a boa prática avaliativa no ensino superior na perspectiva de estudantes. Interface. 2006;10:443-56. doi: 10.1590/ S1414-32832006000200012.

17 Ovigli DFB, Silva EB. Microrganismos? Sim, na saúde e na doença! Aproximando universidade e escola pública. Em: Anais do I Simpósio Nacional de Ensino de Ciência e Tecnologia. Paraná: 2009.

18 Neto LS, Diniz JA. Pesquisa-ação sobre aprendizagem de microbiologia no ensino médio. Ensino, Saúde e Ambiente 2016;9(2):12-26. doi: 10.22409/resa2016. v9i2.a21221.

19 Borges RMR, Lima VMR. Tendências contemporâneas do ensino de Biologia no Brasil. REEC 2007;6(1):165-75.

20 Luckesi CC. Tendências pedagógicas na prática escolar. In: Filosofia da educação. São Paulo: Cortez; 1991. p. 53-75.

21 Penteado TCZ, Guzzo RSL. Educação e psicologia: a construção de um projeto político-pedagógico emancipador. Psicol Soc. 2010;22(3):569-77. doi: 10.1590/S010271822010000300017 .

22 Moresco TR, Carvalho MS, Klein V, Lima AS, Barbosa NV, Rocha JB. Ensino de microbiologia experimental para Educação Básica no contexto da formação continuada. REEC. 2017;16(3):435-57.

23 Andrade EC, Leite ICG, Rodrigues VO, Cesca MG. Parasitoses Intestinais: uma revisão sobre seus aspectos sociais, epidemiológicos, clínicos e terapêuticos. Rev APS. 2010;13(2):231-40.

24 Gazzinelli MF, Gazzinelli A, Reis DCD, Penna CMD. Educação em saúde: conhecimentos, representações sociais e experiências da doença. Cad Saúde Pública. 2005;21(1):2006. doi: 10.1590/S0102-311X2005000100022. 
25 Silva CMC, Meneghim MDC, Pereira AC, Mialhe FL. Educação em saúde: uma reflexão histórica de suas práticas. Ciênc. Saúde Colet. 2010;15(5):2539-50. doi: 10.1590/S141381232010000500028 .

26 Oda W, Delizoicov D. Docência no Ensino Superior: as disciplinas Parasitologia e Microbiologia na formação de professores de Biologia. Rev. Bras. Pesqui. Educ. Cienc. 2011;11(3):101-22.

27 Oliveira VDRB, Garavello CRG, Miguel MMB, Nascimento EG. A prática pedagógica e a formação de professores de Ciências e biologia: uma experiência em construção. In: Anais do VI Encontro Nacional de Pesquisa em Educação em Ciências, 2007, Florianópolis. Florianópolis: UFSC; 2007.

28 Oliveira HM, Gonçalves MJF. Educação em Saúde: uma experiência transformadora. Rev. Bras. Enferm. 2004;57(6):761-3. doi: 10.1590/ S0034-71672004000600028.

29 Viveiro AA, Diniz RES. Atividades de campo no ensino das ciências e na educação ambiental: refletindo sobre as potencialidades desta estratégia na prática escolar. Ciênc Tela. 2009;2(1):1-12.

30 Candeias JMG, Hiroki KAN, Campos LML. A utilização do jogo didático no ensino de microbiologia no ensino fundamental e médio. In: Pinho SZ, Saglietti JRC, organizadores. Núcleos de ensino da Unesp. São Paulo: Cultura Acadêmica; 2007. p. 595-603.

31 Braga C, Avellar M, Cardoso MC, Haueisen M, Alvarenga J. Modelos didáticos para o ensino de ascaridíase (didatic models for the ascariasis teaching). Sinapse Múltipla, 2018;7(2):160-4.

32 Gomes JP. As Escolas Promotoras de Saúde: uma via para promover a saúde e a educação para a saúde da comunidade escolar. Educ. 2009;32(1):84-91.

33 Ribeiro E. A perspectiva da entrevista na investigação qualitativa. Evidência. 2008;4(4):129-48.
34 Medina, L.S.; Klein, T.A.S. Análise dos conhecimentos prévios dos alunos do ensino fundamental sobre o tema "microorganismos". In: Anais do XVI Semana da Educação e VI Simpósio de Pesquisa e Pós-graduação em Educação "Desafios Atuais para a Educação", 2015, Londrina. Londrina: UEL; 2015. p.48-52.

35 Ausubel DP. Aquisição e retenção de conhecimentos: uma perspectiva cognitiva. Lisboa: Plátano Edições Técnicas; 2003.

36 Higa MG Jr. Higienização das mãos: ações lúdicoeducacionais para alunos do Ensino Básico. In: Silva BR Neto. Saúde pública e saúde coletiva: dialogando sobre interfaces temáticas. Ponta Grossa: Atena; 2019. p. 94102. doi: 10.22533/at.ed.86019020911. 
